\title{
The Effect of Mindfulness Meditation on Therapists' Body-Awareness and Burnout in Different Forms of Practice
}

\begin{abstract}
:
Objectives: The main aim of this study was to explore whether mindfulness increases therapists' (physiotherapists and sport therapists) body-awareness and if it can have an effect on reducing their burnout in the workplace. Additionally, it was intended to gather evidence about which of the methods of delivery of the mindfulness meditation programmes (MMP) (face-to-face groups with an instructor (FFGs) and self-directed group (SDG)) were more effective with therapists.
\end{abstract}

Methods: Online tools such as the creation of a website, as well as skype and online surveys were used with participants as part of the methodology. Seven measurements were used to assess the effect of mindfulness meditation on therapists after 4 weeks of formal and informal practise.

Results: Our results showed that attention regulation, self-regulation and trusting in FFGs had a significant improvement in pre and post meditation practise. Findings showed significant differences between groups for the FFGs. Particularly, our findings indicated a clear improvement in the acting with awareness, a positive effect of mindfulness, emotional awareness and a reduction in burnout. However, no changes were observed in stress.

Conclusions: This study offers evidence that mindfulness meditation benefited therapists in terms of improving their body-awareness and by reducing their level of burnout at workplace. The benefits of the mindfulness programme were more significant when delivered in a faceto-face programme rather than in a self-directed way. 
Key words: Physiotherapists, sport therapists, mindfulness, meditation, body-awareness, burnout 


\section{Introduction:}

Mindfulness is a way of being in the present moment and observing whatever thoughts and body sensations that might arise into the mind without judgment [1]. The cultivation of mindfulness includes concentrating on the present time, described by openness, acceptance, nosiness and non-judgmental awareness. In this regard, there are three techniques to improve the body awareness, the first is called a body scan which includes scanning the full body from head to feet, and attention is paid at the current time by using both breath awareness and relaxation. Sitting meditation is the second technique that includes mindful-attention through breath meditation and non-judgmental awareness of the thoughts that constantly comes up to the mind. The third techniques is hatha yoga, which involves concentrating on training the breath and extension exercises to enhance relaxation in the musculoskeletal system [2].

La Forge [3] pointed out that the mindfulness training involves five components. The first component is Meditative/Contemplative, which contains non-judgment during performance, focusing on the current moment and guiding attention to the present targets. The second component is Proprioceptive-Awareness, during mindfulness training the muscular activity is confined to between a low to moderate range, besides; concentrating on the muscles, which contribute to movement. The third component is Breath-Centering. The process of breathing includes various techniques which are a main characteristic within mindful training. The next component is Anatomic Alignment, which means anatomical aspects of the body such as the pelvis, spine and trunk. Noteworthy, is the self-discipline involved with the style of the movements and spine alignment which apply to different forms of Mind-Body exercise. The last component is Energy-Centric. Mindfulness training consist of many kinds of positive energy such as, lively, flow of inner energy and more awareness of the physical activities. 
The objective behind mindful training is to notice the feelings inside the body during movements. At the same time, through mindful exercise, it is possible to understand ourselves and our experiences in addition to knowing the patterns which help us see how to behave in certain situations [4]. Mills and Allen [5] concluded that mindful exercise contains the process of improving the moment-to-moment awareness within the movements, situations and breathing. In addition, this improvement in awareness is concerned with whether the movements are integrated into the mind or whether there is a disconnect between the "mind and body", whether the process of breathing is deep or shallow and also whether movement situations are aligned or misaligned. In relation to mindfulness interventions, Baer at el. [6] stated the fact that there are many mechanisms which teach mindful exercise and are applied in the health field, such as (Relapse Prevention for Substance Abuse [7]; Acceptance Commitment Therapy (ACT) [8]; Mindfulness-Based Cognitive Therapy (MBCT) [9] and Mindfulness-Based Stress Reduction [10,11]). A technique that has proven to be effective in developing the participants' awareness is the "body scan" technique once awareness has been achieved movements become more graceful and comfortable, and participants become aware of any muscular tension or cohesion in their movements, as participants developed a deeper understanding of the self-worth of their own body [5].

\section{Therapists and work-related stress:}

Different studies from across the globe have gathered evidence that the physiotherapists work conditions put them in high risk and high levels of stress and anxiety and musculoskeletal problems. In an international study in which the participants were therapists from 35 different countries [12], the majority of therapists reported experiencing extreme fatigue (66\%). In the same study, the international sample of participants mentioned experiencing a series of psychological symptoms such as increased irritability, increased isolation, and sadness or hopelessness and also work related issues were mentioned such as increased difficulty with 
colleagues and decreased productivity. These results were also echoed by another survy-based study [13] conducted in a sample of 243 Iranian physiotherapists, observed that more than a half of the participants of their survey had job related musculoskeletal problems and that $58.2 \%$ of them perceived that their job was a source of stress. It seems that workplace stress in the therapeutic profession is common across cultures. In the United Kingdom, the Chartered Society of Physiotherapy (CSP) conducted a survey in which $37 \%$ of its members reported having unacceptably high stress levels. Moreover a quarter of their physiotherapists who took part in the CSP survey stated that the workplace stress has been detrimental to their health [14].

Another problematic symptom of the physiotherapists' work conditions that has attracted the attention from scholars is compassion fatigue (CF). Compassion fatigue has been characterized as the gradual lessening of compassion and the overall negativity experienced by caregivers who are frequently exposed and work with people who have experienced traumatic stress and/or suffering [15]. The therapists who in Klapa et al. [12] study showed symptoms of CF, reported 'having difficulty demonstrating compassion to their patients while facing the stresses of productivity and other job strains' [12, p.136]. Gh et al. [13] also stated that physiotherapists may be susceptible to chronic fatigue syndrome because they are frequently exposed to work closely with clients who have chronic problems. CF strongly associates with burnout syndrome in physiotherapists. In Pavlakis et al. study [16] one-fifth of physiotherapists presented high levels of burnout signs and work related symptoms of stress.

Overall, there is a plethora of studies evidencing that demands placed on the therapists can potentially lead to heightened levels of stress and burnout [17-20]. Maslach and Jackson [21] clarified that burnout as a psychological condition includes three elements of negative experiences which can be noticed through a reduction in personal achievement, increase in depersonalisation and a high level of emotional fatigue. 
Therapists are conscious of the stress symptoms related to their work conditions and that they are at risk of burnout. In the phenomenological enquiry led by Klapa et al. [12] therapists mentioned the employment of several strategies, such as physical activity and their participation hobbies in their spare time to alleviate the symptoms and achieve a healthier life-work balance [12]. However mindfulness training was not listed among the different copying strategies employed by therapists to reduce their workplace related stress. In the section that follows evidence form the literature is summarized in order to highlight how mindfulness training can help reduce psychological distress [12].

\section{Why mindfulness practise can be of benefit to therapists:}

Notably, and related to the context of this study, the effect of mindfulness training in reducing workplace stress has started to been identified and scholarly evidence has been gathering over the course of the past decade. Dijkstra et al. [22] employed a 3-day residential body awareness program (BAP) directed to people with chronic aspecific psychosomatic symptoms (CAPS) in order to help them cope with their daily workload. The methodological design (pre-post) of that study enabled the authors to gather evidence that BAP can leads to long-term effects in copying with psychosomatic symptoms. A year after the 3-day program, participants had modified their behaviour a way that helped dealing better with their daily worked and coping with stress and psychosomatic symptoms.

The above results have been echoed by another study by Shapiro et al. [23] who observed that healthcare-professionals who received 8 weeks of meditation practice recorded less stress and a greater level of compassion compared to their peers in the control group. In addition, both of negative emotions and burnout had decreased. In a similar vein, Schenström et al. [24] discovered that mindfulness and wellbeing were increased in a mixture of healthcare- 
professionals after participating in a mindfulness program. Additionally, the stress level had decreased both at home and at the workplace.

Therefore, and in light of the above, mindfulness could be a convenient skill that can support therapists in terms of improving their body-awareness, reducing burnout syndromes and achieve compassion and a better mood state.

In our present study, the focus was in exploring the following two research questions:

- Does mindfulness increase therapists' body-awareness and reduce their burnout in the workplace?

- Which of the delivery method of the mindfulness mediation program (face-to-face with an instructor or self-directed)) was more effective with therapists.

\section{Methods:}

\section{Participants:}

A total of 29 therapists were involved in this study (See Table 1). The participants were able to take part in the present study in various locations throughout the world. The primary researcher along with the other investigators contacted the therapists and asked them to take part in this study. Furthermore, the investigators contacted the Chartered Society of Physiotherapists (CSP). A request for potential participants and the contact details of the researcher were posted in the CSP forum for Skype and an online survey. Therapists in the Medway were also contacted for the face-to-face group. The graduate sports therapists were contacted though the School of Exercise and Sports Sciences' social media. The participants were allocated to either group A): face to face and face to face through Skype (FFGs) or the 
group B): Self-directed (SDG) group. UK therapists were allocated to the FFGs but the nonUK therapists were allocated to the SDG. It should be also noted that, therapists in the intervention group were given formal mindfulness meditation practice with the primary researcher for 60-90 minutes per week. In addition they were asked to continue to practice 2030 minutes of informal mindfulness meditation training through listening to a $\mathrm{CD}$ of the "mindfulness based stress reduction workbook" by Stahl \& Goldstein [1]. Regarding to the self-directed group SDG, therapists only practised 20-30 minutes of informal mindfulness meditation training on their own. The details of differences in terms of applying MMP, completing the quantitative measurements and time were presented in (Table 2).

\section{Materials:}

In this study, internet based technologies such as websites, skype conference calls and online surveys were used with participants as part of the methodology. The website: http://mindfullnessmeditationresearch.weebly.com/ was created exclusively for the purpose of the study and to make the study procedure and data collection easier. Moreover, the website was also set up to avoid some technical issues that might have an effect on the study process such as wasting time, not receiving data properly, losing data and having contact difficulties. Further, a skype interview call was utilised with a group of participants to practice MMP for 60 to 90 minutes per week. Finally, therapists completed all the questionnaires, which had seven scales with different purposes through an online survey. All quantitative measurements that have been utilised in this study were validated and the Cronbach alpha for each questionnaire presented in below. 


\section{Burnout Self-Test, (BST) Maslach Burnout Inventory (MBI) [21]}

The MBI is comprised of 22 items, each divided into three sections. The MBI rating is between 0 (never) to 6 (every day. With regard to the Cornbach's alpha for each subscale, the figures were 0.90 for Burnout, 0.79 for Depersonalisation and 0.71 for Personal Achievement [21]. Furthermore, Loera et al. [25] emphasised that MBI is extensively used to assess burnout, by using three subscales: personal accomplishment, depersonalisation and emotional personal. In this study MBI was utilised with therapists to discover their attitudes and feelings pre and post the MMP. Essentially, each subscale has a particular score to measure MBI/BST. For instance, a low-level of burnout starts with total scores of 17 or less, moderate burnout is between the total of 18 to 29 , and a high-level of burnout with a total of 30 or more. Depersonalisation scores are measure low-burnout from 5 or less, moderate-burnout from 611, and high-burnout from 12 or more. Regarding to the personal achievement scores, a high level of burnout is a total of 33 or less. Whereas, the moderate burnout is from 33-39 and more than 40 which indicates a high level of burnout [21].

\section{Multidimensional Assessment of Interoceptive Awareness (MAIA) [26]}

MAIA was developed by Mehling et al. [26] at the University of California, San Francisco. This instrument included 32 items to measure eight notions of interoceptive awareness which are noticing, not-distracting, worrying, emotional awareness, attention regulation, body listening, trusting and self-regulation. This scale includes some reverse-score items particularly on not-distracting and worrying subscales. Afterward, total scores are calculated for each subscale. The Cornbach's alpha for MAIA subscales is: 0.69 for Noticing, 0.66 for Not-Distracting, 0.67 for Not-Worrying, 0.87 for Attention-Regulation, 0.82 for EmotionalAwareness, 0.83 for Self-Regulation, 0.82 for Body- Listening and 0.79 for Trusting [26].The rating scale is divided between 0 (never) to 5 (always). Mehling et al. [26] indicated that an interoceptive awareness is a state of conscious perception of internal body sensations, 
which can be sensed through physiological conditions such as respiration, heartbeat, satiety and autonomic nervous system sensations. Furthermore, this instrument is much related with mindfulness meditation and it has been commonly used in assessing body sensations [26].

\section{Five Facet Mindfulness Questionnaire (FFMQ) [27]}

The initial FFMQ was developed by Baer et al. [27] this instrument included 39 items that measured five components, such as non-judging ( $\mathrm{NJ}$ ) of inner experience eight items, nonreactivity to inner experience (NR) eight items, acting with awareness (AA) eight items, describing (DS) eight items and observing (OB) eight items. The FFMQ scale rating is from 1: "never or very rarely true" to 5: "very often or always true". The Cornbach's alpha for all subscales were 0.81 for Observing, 0.87 for Describing, 0.83 for Acting with Awareness, 0.83 for Non-Judging and 0.75 for the Non-Reactivity [28]. Additionally to the previous scale, FFMQs also have reverse score items, describing by $(\mathrm{R})$ and then summing all items to achieve the total scores of FFMQ [28]. In the current study, a short form of the FFMQ was utilised, which was developed by Bohlmeijer et al. [28].

\section{Santa Clara Brief Compassion Scale (SCBCS) [29]}

The original version of the Compassionate Love Scale consisted of 21 items [29]. The updated version of the SCBCS was developed by Hawang et al. [29]. In addition, it included five items and the purpose of the SCBCS was to assess compassion and it is associated with prosocial behaviours. The higher the score, the greater the compassion, and the scale is divided into seven points from "not at all true of me" to "very true of me". The Cornbach's alpha for the SCBCS is 0.90 [30]. Hawang et al. [29] emphasised that to investigate the effectiveness of any educational strategies, the SCBCS is an ideal tool to assess compassion between respondents. Besides, the SCBCS is short and therefore the process of scoring and analysing becomes easier. A study by Plante and Mejia [31] indicated that SCBCS is an 
appropriate and valid scale to measure self-reported compassion. This was done through different psychometric tests and the collection of data from 6,763 responses.

\section{The Positive and Negative Affect Schedule (PANAS) [32]}

The PANAS is designed as a valid and reliable instrument to evaluate both negative and positive moods, through 20 words (10 negative and 10 positive) that express different emotions for respondents. Each word is given a rating between $1=$ very slightly or not at all to $5=$ extremely. The participants selected the numbers according to how he/she felt in the present moment [32]. Positive or negative scores ranged between 10-50 with higher scores indicting higher rates of positive or negative affect. The Cornbach's alpha for the positive scale is ranged between 0.86 to 0.90 and the negative scale from 0.84 to 0.87 [32]. Therefore, PANAS was a convenient means to use in the present study to distinguish the emotional state for therapists. In addition, Schmukle et al. [33] stressed that PANAS is the most common instrument that is used in numerous studies regarding health complaints, perceived stress and social activities [34-37].

\section{Perceived Stress Scale (PSS) [38]}

PSS is widely applied as a psychological means to measure the perception of stress. Therefore, the PSS is a convenient scale to investigate the present level of stress. Additionally, through this instrument, it is possible to understand both thoughts and feelings for respondents during the last month. After reverse coding, some items and then all the items are summed to obtain the total PSS scores. Furthermore, the Cornbach's alpha for PSS 10 items is 0.78 [38]. Cohen and Williamson [38] and Andreou et al. [39] mentioned that to measure the perception of stress, there are three common instruments which are Impact of Event Scale IES, Stress Appraisal Measure SAM and the Perceived Stress Scale PSS. Notably, PSS is the most popular instrument that is used in particular studies such as stress 
management strategies, assessing the stressfulness of events and physical and psychiatric diseases.

\section{The Depression, Anxiety and Stress Scale (DASS 21) [40]}

The original version of DASS [40] comprised 42 items measuring 3 scales of depression, anxiety and stress and each scale contained 14 items. In contrast, DASS 21 is developed from the original DASS and each subscale has 7 items; notably, DASS21 has high validity and reliability. The Cornbach's alpha for all DASS 21 subscales are 0.91 for Depression, 0.81 for Anxiety and 0.89 for Stress. The rating scale is scored between 0 (never) to 3 (almost always) [40]. DASS 21 scores have five levels of severity for each subscale which are normal, mild, moderate, severe and extremely severe.

Further, DASS 21 requires less time to complete compared to the DASS; therefore, it will be more acceptable for participants in two dimensions. The first are participants who have busy schedules and the second participants with a limited focus [41]. In this study the DASS 21 [40] was utilised with therapists.

\section{Procedure:}

This study has been approved by the School of Sport and Exercise Sciences, Ethics Committee. Three pilot tests were conducted to test the design of this study. Prior to the data collection, all the assessment tools that were used in the present study were transferred to the online version. The first pilot test was to design one of these questionnaires giving two ways to answer. The purpose of that was to understand which way would be easier to handle the data collection. The first design, which included three questions to be completed, then enabled the participants to skip to other questions. The second design, included one question to complete, and then the participants could skip to the next question. Notably, ten postgraduate 
students completed both designs of the questionnaire via PC and mobile. As a result, the first design was chosen by the participants who took part in this study, because they emphasised that it was easier and quicker. Five postgraduate students were involved in the second pilot test to identify the length of time taken for all the questionnaires that were used in the present study. The last pilot test was done with three therapists entering a website which was created to handle all the data collection in this study. The participants read and completed consent forms and all the questionnaires. Additionally, the primary researcher was sitting next to them and noting down any observations that he/she might have had to do, or any other points that were not understood.

The study lasted 4 weeks in total and all the information regarding the structure of the study was given to the participants during that period. It should be noted that, mindfulness practise (MP) in this study was based on the Mindfulness Based Stress Reduction that was developed by Kabat-Zinn in 1979 at the University of Massachusetts Medical Centre in Worcester, USA. See Table (2). Importantly, the original MBSR had been offered for 8 weeks with 2.30 minutes of formal and informal practice. In this study, the MMP had been modified into 4 weeks to be convenient for therapists in terms of time and study procedure. The reason behind that was that therapists in the SDG came from different countries. As such, therapists in both groups had limited availability to participate in 8 weeks MMP. Furthermore, there were many requirements that the therapists were asked to complete, therefore asking more might have affected their participation.

The baseline measures (questionnaires) were taken before and after four weeks. Once they complete the questionnaires they started training and practising mindfulness. It should be noted that, in this study MMP was used with 2 different groups. The first group was the therapists, who trained in mindfulness face to face (FFGs) with the researcher. Each week involved one session lasting 60 to 90 minutes. Further, each participant was given one CD 
from the MBSR program to listen to and practice at home for about 20 minutes per day. Some of the therapists in the face to face group practiced mindfulness via skype that was led by the researcher and lasted 60 to 90 minutes.

The second group were self-directed (SDG) participants who applied the MMP by themselves, using a CD that was provided to them. The outcomes were collected via an online survey. It is noteworthy that all questionnaires were completed on-line at two different times. The first time was when the participants filled in all the questionnaires at the beginning of the four weeks. The last time was when the participants filled in questionnaires after they had done the mindfulness program. Notably, therapists in SDG were obtained the guides from the $\mathrm{CD}$ of MBSR. In other words, the CD consists of instructions that meditators need during meditation practice. Additionally, as mentioned above, all therapists received further information in the consent form regarding to the study procedure and meditation procedure before their participation in this study.

Table 1: Demographic information and details of each therapist in terms of Age, Gender, Qualifications and Country.

\section{Groups:}

\begin{tabular}{|c|c|c|c|c|}
\hline Face to Face & \multicolumn{1}{|l|}{ Age } & Gender & Field & Country \\
\hline A1 & 32 & M & Physiotherapist & UK \\
\hline A2 & 25 & M & Sport therapist & UK \\
\hline A3 & 34 & F & Physiotherapist & UK \\
\hline A4 & 35 & M & Sport therapist & UK \\
\hline A5 & 23 & F & Sport therapist & UK \\
\hline A6 & 27 & F & Physiotherapist & UK \\
\hline A7 & 23 & M & Sport therapist & UK \\
\hline A8 & 24 & M & Sport therapist & UK \\
\hline
\end{tabular}




\begin{tabular}{|c|c|c|c|c|}
\hline A9 & 22 & M & Sport therapist & UK \\
\hline A10 & 23 & $\mathrm{~F}$ & Sport therapist & UK \\
\hline \multicolumn{5}{|c|}{ Face to Face via Skype: } \\
\hline A11 & 35 & $\mathrm{~F}$ & Sport therapist & Thailand \\
\hline A12 & 25 & $\mathrm{~F}$ & Physiotherapist & Lithuania \\
\hline A13 & 34 & $\mathrm{M}$ & Physiotherapist & Brazil \\
\hline A14 & 35 & $\mathrm{~F}$ & Physiotherapist & India \\
\hline A15 & 36 & $\mathrm{M}$ & Physiotherapist & Kurdistan/Iraq \\
\hline A16 & 33 & $\mathrm{M}$ & Physiotherapist & Brazil \\
\hline \multicolumn{5}{|c|}{ Self-Directed: } \\
\hline B1 & 27 & $\mathrm{M}$ & Physiotherapist & Thailand \\
\hline B2 & 32 & $\mathrm{M}$ & Physiotherapist & Brazil \\
\hline B3 & 35 & $\mathrm{M}$ & Physiotherapist & Italy \\
\hline B4 & 36 & $\mathrm{M}$ & Physiotherapist & Kurdistan/Iraq \\
\hline B5 & 38 & $\mathrm{~F}$ & Physiotherapist & India \\
\hline B6 & 32 & $\mathrm{~F}$ & Physiotherapist & Kurdistan/Iraq \\
\hline B7 & 27 & M & Physiotherapist & India \\
\hline B8 & 45 & $\mathrm{~F}$ & Physiotherapist & India \\
\hline B9 & 25 & $\mathrm{~F}$ & Physiotherapist & Brazil \\
\hline B10 & 40 & M & Physiotherapist & Kurdistan/Iraq \\
\hline B11 & 35 & M & Physiotherapist & Brazil \\
\hline B12 & 35 & $\mathrm{~F}$ & Sport therapist & Brazil \\
\hline B13 & 35 & M & Sport therapist & India \\
\hline
\end{tabular}


Table 2: Mindfulness Meditation Program (MMP) that was used in this study with injured athletes, and all sessions were led by the primary researchers. While, the therapists in the SDG applied MMP by themselves via a mediation practice CD.

\begin{tabular}{|c|c|c|}
\hline Weeks & $\begin{array}{l}\text { Formal mindfulness meditation } \\
\text { practice }(60-90) \text { minutes (face to } \\
\text { face and skype groups). }\end{array}$ & $\begin{array}{c}\text { Informal mindfulness meditation } \\
\text { practise with daily (20) minutes of } \\
\text { informal training (Self-Directed } \\
\text { group). }\end{array}$ \\
\hline $\begin{array}{c}\text { Week } \\
0\end{array}$ & 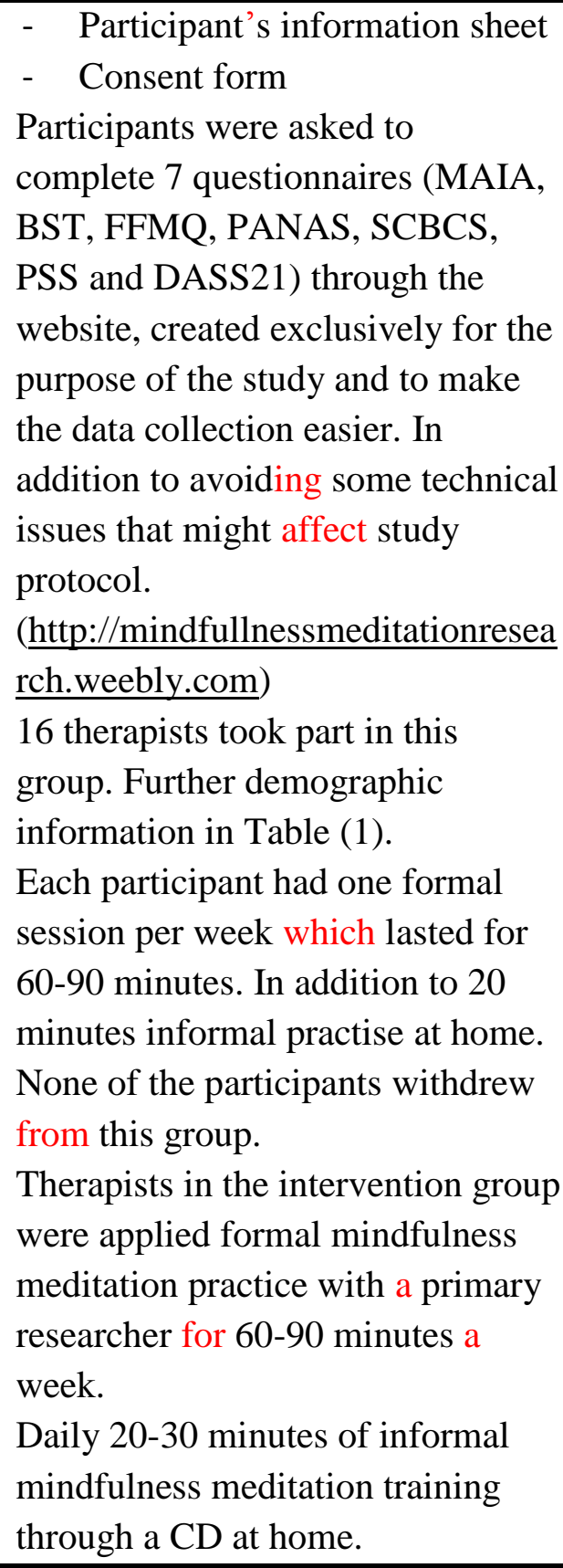 & $\begin{array}{l}\text { - Participant's information sheet } \\
\text { - Consent form } \\
\text { Participants were asked to complete } \\
7 \text { questionnaires (MAIA, BST, } \\
\text { FFMQ, PANAS, SCBCS, PSS and } \\
\text { DASS21) through the website, } \\
\text { created exclusively for the purpose of } \\
\text { the study and to make the data } \\
\text { collection easier. In addition to } \\
\text { avoiding some technical issues that } \\
\text { might affect study protocol. } \\
\text { (http://mindfullnessmeditationresearc } \\
\text { h.weebly.com) } \\
\text { 13 therapists took part in this group. } \\
\text { Further demographic information in } \\
\text { Table (1). } \\
\text { Participants were only applied } \\
\text { mindfulness meditation by } \\
\text { themselves, with CD guides for only } \\
20 \text { minutes per day. } \\
\text { Only } 7 \text { participants withdraw from } \\
\text { this group, after they singed } \\
\text { informed consent without any } \\
\text { explanation. } \\
\text { Therapists in the Self-directed group } \\
\text { SDG, were only practised } 20-30 \\
\text { minutes of informal mindfulness } \\
\text { meditation training by themselves. }\end{array}$ \\
\hline $\begin{array}{l}\text { Week } \\
1 \text { to } \\
\text { Week } \\
4\end{array}$ & $\begin{array}{l}\text { The formal session protocol. } \\
\text { - } 10 \text { to } 15 \text { minutes mindful check- } \\
\text { in and sharing ideas about } \\
\text { mindfulness meditation practice. } \\
\text { - } 35 \text { minutes formal meditation }\end{array}$ & $\begin{array}{l}\text { The informal session protocol. } \\
20 \text { minutes of daily mindfulness } \\
\text { meditation through the CD guide. } \\
\text { The CD of MBSR were included } \\
\text { these skills (sitting/laying down }\end{array}$ \\
\hline
\end{tabular}




\begin{tabular}{|c|c|c|}
\hline & $\begin{array}{l}\text { practice. The formal session was } \\
\text { included these meditation skills } \\
\text { (sitting or lay down meditation, } \\
\text { mindful breathing and body- } \\
\text { scan meditation). } \\
10 \text { to } 15 \text { minutes mindful check- } \\
\text { in and sharing ideas about } \\
\text { mindfulness meditation practice. } \\
\text { As well as this, sharing attitude } \\
\text { that emerged from the session. }\end{array}$ & $\begin{array}{l}\text { meditation, mindful breathing, body- } \\
\text { scan meditation, mindful walking } \\
\text { meditation, mindful eating, } \\
\text { meditation for anxiety and stress, } \\
\text { mindful lying yoga, mindful standing } \\
\text { yoga and loving kindness } \\
\text { meditation). }\end{array}$ \\
\hline $\begin{array}{c}\text { Week } \\
5\end{array}$ & $\begin{array}{l}\text { Participants were asked for the } \\
\text { second time to complete } 7 \\
\text { questionnaires (MAIA, BST, } \\
\text { FFMQ, PANAS, SCBCS, PSS and } \\
\text { DASS21) through the website } \\
\text { below: } \\
\text { (http://mindfullnessmeditationresea } \\
\text { rch.weebly.com/) }\end{array}$ & $\begin{array}{l}\text { Participants were asked for the } \\
\text { second time to complete } 7 \\
\text { questionnaires (MAIA, BST, FFMQ, } \\
\text { PANAS, SCBCS, PSS and DASS21) } \\
\text { through the website below: } \\
\text { (http://mindfullnessmeditationresearc } \\
\underline{\text { h.weebly.com/) }}\end{array}$ \\
\hline
\end{tabular}

\section{Results}

The data were analysed based on either parametric (e.g. t-test) if data conformed to a normal distribution, or non-parametric statistics were reported, e.g. a z-score using a Wilcoxon signed ranked test, or a Mann Whitney U Test, (see Table 3, 4, 5).

\section{Multidimensional Assessment of Interceptive Awareness (MAIA)}

The total findings of the MAIA showed that there were no significant differences in pre and post meditation scores for the SDG $(\mathrm{z}=-0.54, \mathrm{p}=0.59)$. Furthermore, pre and post meditation scores in the face to face group were significant $(\mathrm{z}=-2.80, \mathrm{p}=0.05)$.

In addition, the results showed significant differences between the groups in mean difference scores $(\mathrm{u}=2.50 \mathrm{p}=0.034)$.

The focus will be on three subscales which have been significantly improved after MMP. 
1. Attention Regulation (AR)

Regarding to the AR subscale our findings indicate that FFGs had significant differences in

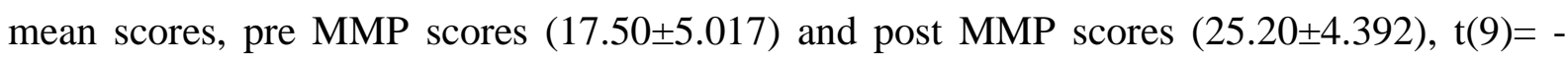
4.478, $\mathrm{p}=0.002$. On the other hand, there were no changes in the pre mean scores for SDG $(17.75 \pm 9.179)$ and post MMP scores $(15.67 \pm 10.693), \mathrm{p}=0.235$.

2. Self-Regulation (SR)

The data showed that there were improvements in the mean scores of FFGs, pre MMP scores $(9.60 \pm 3.806)$ and post MMP scores $(14.80 \pm 2.044), t(9)=-5.600, p<0.001$. Whereas, there were

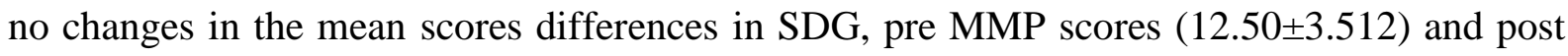
MMP scores $(12.00 \pm 8.185), \mathrm{t}(2)=1.677, \mathrm{p}=0652$.

3. Trusting

As such, the findings showed that there were clear improvements in the mean scores for FFGs, pre MMP scores (9.20 \pm 3.360$)$ and post MMP scores $(11.80 \pm 2.860), \mathrm{t}(9)=-4.628$, $\mathrm{p}=0.001$. While, no changes were found in SDG pre MMP scores $(10.00 \pm 3.916)$ and post MMP scores $(9.67 \pm 4.163), \mathrm{t}(2)=0.311, \mathrm{p}=0.785$.

\section{Burnout Self-Test and the Maslach Burnout Inventory (BST/MBI)}

1. Burnout/ Emotional Exhaustion

Burnout/BST scores showed that the FFGs had remarkable differences in the mean scores, pre meditation scores $(9.60 \pm 6.7)$ and post meditation scores $(13.20 \pm 10.94), t(9)=-2.17, \mathrm{p}=0.058$. However, data revealed that there were no significant differences in the mean scores for the SDG. Burnout/BST scores in the pre meditation were $(13 \pm 3.61)$ and in the post meditation scores $(14.33 \pm 10.01), \mathrm{t}(2)=-0.359, \mathrm{p}=0.754$.

Moreover, there were no notable changes observed between groups in their mean difference SDG $(1.33 \pm 6.42)$ and FFGs scores $(3.6 \pm 5.25), \mathrm{t}(11)=0.628, \mathrm{p}=0.628$. 
However there was no significant difference found in SDG. The change in score was calculated between the pre and post meditation scores and compared between groups. However, no difference was found.

2. Depersonalisation

Data showed that there were no differences in the pre meditation depersonalisation/BST scores $(17.75 \pm 10.05)$ and post meditation scores $(14 \pm 3.61)$ for the self-directed group $(\mathrm{z}=-$ 0.54, $\mathrm{p}=0.59$ ). Likewise, depersonalisation /BST scores in the face to face group were not

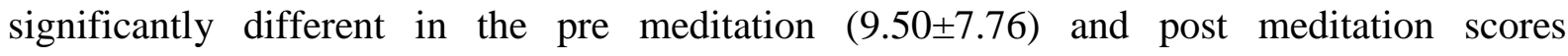
$(6.40 \pm 5.50)$ and $(\mathrm{z}=-1.72, \mathrm{p}=0.09)$.

In addition, the result revealed that there were no significant differences were found in the mean change scores between SDG $(1 \pm 4.58)$ and FFGs $(-3.1 \pm 6.15)$, in the mean difference $(4.53 \pm 5.66)$ scores $(\mathrm{u}=13, \mathrm{P}=0.733)$.

3. Personal Achievement

The Wilcoxon signed - Rank test indicated that there was no significant difference in pre and post meditation scores for the self-directed group $(\mathrm{z}=-0.82, \mathrm{p}=0.41)$.

However, there were clear differences in the pre and post meditation scores in the face to face $\operatorname{group}(\mathrm{z}=-2.30, \mathrm{p}=0.021)$.

Notably, there was no significant difference between the FFGs and SDG in the mean difference scores $(\mathrm{u}=13, \mathrm{p}=0.733)$.

\section{Five Faced Mindfulness Questionnaire: short form (FFMQ-SF)}

Total scores for FFMQ showed that there were no significant differences in pre and post meditation scores for $\mathrm{SDG}(\mathrm{z}=-1.07, \mathrm{p}=0.28)$ and pre and post meditation scores in FFGs $(\mathrm{z}=-$ $1.17, \mathrm{p}=0.24)$. 
It is noteworthy that, there was no significant difference between the groups in the mean difference scores $(\mathrm{u}=12 \mathrm{p}=0.610)$.

Acting with Awareness (AA)

Our findings showed that AA was significantly improved after MMP. The data revealed that the mean scores in pre MMP scores for FFGs $(8.30 \pm 2.497)$ and post $(6.60 \pm 1.955), t(9)=3.431$, $\mathrm{p}=008$. However, the changes have not been observed in SDG in pre MMP scores (9.20 \pm 1.789$)$ and post MMP $(9.33 \pm 2.082), \mathrm{t}(2)-5.555, \mathrm{p}=0.635$. Furthermore, the findings have been indicated that there were significant differences between groups $t(11)=2.098$, $\mathrm{p}=0.945$.

\section{Santa Clara Brief Compassion Scale (SCBCS)}

The scores found the FFGs had a significant difference in mean score SCBC pre meditation 23.50 \pm 5.359 and a post meditation score of $27.60 \pm 4.03, \mathrm{t}(9)=-2.527, \mathrm{p}=0.032$. However, there was no significant difference found in the SDG pre mediation scores $(25 \pm 6.03)$ and post $(21 \pm 9.53), \mathrm{t}(2)=0.327, \mathrm{p}=0.775$.

The changes in score were calculated between the pre and post meditation scores and compared between groups. Nevertheless, no notable differences were found.

\section{The Depression, Anxiety and Stress Scale (DASS 21)}

Total results in DASS 21, indicated that there were no significant differences in the SDG in

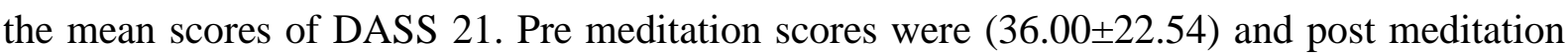
scores were $20.67 \pm 5.03, \mathrm{t}(2)=1.482$., $\mathrm{p}=0.277$. 
Results showed that there were no significant differences in the mean scores of DASS 21 found in the FFGs. Data revealed that pre meditation scores were $(30.00 \pm 14.36)$ post meditation scores were $(21.00 \pm 13.67), \mathrm{t}(9)=1.853, \mathrm{p}=0.093$.

Besides, there were no differences observed between groups in their mean differences SDG ($15.33 \pm 17.9)$ and FFGs $(-9 \pm 15.35), t(11)=0.607, p=0.649$.

\section{The Positive and Negative Affect Schedule (PANAS)}

Total PANAS scores, showed that there was no significant difference in pre and post meditation scores for the SDG $(\mathrm{z}=-0.54, \mathrm{p}=0.593)$. However, in the FFGs, data showed changes in pre and post meditation scores $(\mathrm{z}=-2.72, \mathrm{p}=0.005)$.

Additionally, the $U$ test showed that there were significant differences between the groups in the mean difference scores $(\mathrm{u}=3, \mathrm{p}=0.042)$.

Positive Affect (PA)

The positive affect scores showed that there was a difference in the mean scores of FFGs in pre MMP scores (31.30 \pm 8.056$)$ and post MMP scores $(39.70 \pm 2.830), \mathrm{t}(9)=-3.763, \mathrm{p}=0.004$. On the other hand, no changes were found in SDG in pre MMP scores $(33.25 \pm 6.076)$ and post MMP scores $(33.00 \pm 12.124), \mathrm{t}(2)=0.346, \mathrm{p}=0.762$.

Additionally, findings showed that PA has significantly changed between groups in this study $\mathrm{t}(9)=-3.763, \mathrm{p}=0.004$.

\section{Perceived Stress Scale (PSS)}

PSS results showed that there were no significant differences in both pre and post meditation scores for the SDG ( $\mathrm{z}=-1.604, \mathrm{p}=0.11)$. Likewise, almost significant changes were found in pre and post meditation scores in the FFGs $(\mathrm{z}=-1.89, \mathrm{p}=0.058)$ have been found. 
Furthermore, no changes were found between the groups in the mean difference scores $(u=10$, $\mathrm{p}=0.39)$.

Table 3: Analysis for the self-directed meditation group comparing pre with post meditation

\begin{tabular}{|c|c|c|c|c|}
\hline \multicolumn{2}{|c|}{ Outcome Variable } & $\begin{array}{c}\text { Pre } \\
\text { Meditation }\end{array}$ & $\begin{array}{c}\text { Post } \\
\text { Meditation }\end{array}$ & $\begin{array}{c}\text { Statistical } \\
\text { analyses } \\
\text { values } \\
(\mathbf{t} / \mathbf{z}, \mathbf{p})\end{array}$ \\
\hline \multicolumn{2}{|c|}{$\begin{array}{l}\text { Multidimensional Assessment of } \\
\text { Interceptive Awareness (MAIA). }\end{array}$} & $87.25 \pm 17.84$ & $83.33 \pm 31.89$ & $\begin{array}{l}\mathrm{z}=-\mathbf{0 . 5 3 5} \\
\mathrm{p}=\mathbf{0 . 5 9 3}\end{array}$ \\
\hline \multicolumn{2}{|c|}{ Attention Regulation (MAIA) } & $\mathbf{1 7 . 7 5} \pm 9.17$ & $15.67 \pm 10.69$ & $\begin{array}{l}t(2)=1.677, p \\
=0.235\end{array}$ \\
\hline \multicolumn{2}{|l|}{ Self-Regulation (MAIA) } & $12.50 \pm 3.51$ & $12.00 \pm 8.18$ & $\begin{array}{l}t(2)=0.524, p \\
=0.652\end{array}$ \\
\hline \multicolumn{2}{|l|}{ Trusting (MAIA) } & $10.00 \pm 3.91$ & $9.67 \pm 4.16$ & $\begin{array}{l}t(2)=0.311, p \\
\quad=0.785\end{array}$ \\
\hline \multirow[t]{3}{*}{$\begin{array}{l}\text { Burnout Self-Test and the } \\
\text { Maslach } \quad \text { Burnout } \\
\text { Inventory (BST/MBI) }\end{array}$} & Burnout & $13 \pm 3.61$ & $14.33 \pm 10.01$ & $\begin{array}{l}t=-0.359 \\
p=0.754\end{array}$ \\
\hline & $\begin{array}{l}\text { Depersonalisatio } \\
\text { n }\end{array}$ & $17.75 \pm 10.05$ & $14 \pm 3.61$ & $\begin{array}{c}\mathrm{z}=\mathbf{- 0 . 5 3 5} \\
\mathrm{p}=\mathbf{0 . 5 9 3}\end{array}$ \\
\hline & $\begin{array}{l}\text { Personal } \\
\text { Achievement }\end{array}$ & $27 \pm 10.06$ & $33 \pm 13$ & $\begin{array}{r}\mathrm{z}=-\mathbf{0 . 8 1 6} \\
\mathrm{p}=\mathbf{0 . 4 1 4}\end{array}$ \\
\hline \multicolumn{2}{|c|}{$\begin{array}{l}\text { Five Faced Mindfulness questionnaire: short } \\
\text { form (FFMQ-SF) }\end{array}$} & $60.80 \pm 10.91$ & $67.66 \pm 0.57$ & $\begin{array}{l}z=-1.069 \\
p=0.285\end{array}$ \\
\hline \multicolumn{2}{|c|}{ Acting with Awareness (FFMQ-SF) } & $9.20 \pm 1.78$ & $9.33 \pm 2.08$ & $\begin{aligned} \mathbf{t}(2) & =-0.555 \\
\mathbf{p} & =0.635\end{aligned}$ \\
\hline \multicolumn{2}{|c|}{ Santa Clara Brief Compassion Scale (SCBC) } & $25 \pm 6.03$ & $21 \pm 9.53$ & $\begin{array}{l}t=0.327 \\
p=0.775\end{array}$ \\
\hline \multicolumn{2}{|c|}{ The Depression, Anxiety and Stress Scale } & $36.00 \pm 22.54$ & $20.67 \pm 5.03$ & $t=1.482$ \\
\hline
\end{tabular}




\begin{tabular}{|c|c|c|c|}
\hline (DASS 21) & & & $p=0.277$ \\
\hline $\begin{array}{l}\text { The Positive and Negative Affect Schedule } \\
\text { (PANAS) }\end{array}$ & $33.25 \pm 6.08$ & $33 \pm 12.12$ & $\begin{array}{r}\mathrm{z}=-\mathbf{0 . 5 3 5} \\
\mathrm{p}=\mathbf{0 . 5 9 3}\end{array}$ \\
\hline Positive Affect of (PANAS) & $33.25 \pm 6.07$ & $33.00 \pm 12.12$ & $\begin{array}{l}t(2)=0.346, p \\
\quad=0.762\end{array}$ \\
\hline Perceived Stress Scale & $24.75 \pm 7.50$ & $15.33 \pm 1.15$ & $\begin{array}{c}z=-1.604 \\
p=0.109\end{array}$ \\
\hline
\end{tabular}

Table 4: Analysis of face to face meditation groups comparing pre and post meditation

\begin{tabular}{|c|c|c|c|c|}
\hline \multicolumn{2}{|c|}{ Outcome Variable } & $\begin{array}{c}\text { Pre } \\
\text { Meditation }\end{array}$ & $\begin{array}{c}\text { Post } \\
\text { Meditation }\end{array}$ & $\begin{array}{c}\text { Statistical } \\
\text { analyses } \\
\text { values } \\
(\mathbf{t} / \mathbf{z}, \mathbf{p})\end{array}$ \\
\hline \multicolumn{2}{|c|}{$\begin{array}{l}\text { Multidimensional Assessment of } \\
\text { Interceptive Awareness (MAIA). }\end{array}$} & $82 \pm 21.69$ & $110 \pm 11.96$ & $\begin{array}{c}\mathrm{z}=-2.80, \mathrm{p}= \\
0.005\end{array}$ \\
\hline \multicolumn{2}{|c|}{ Attention Regulation (MAIA) } & $17.50 \pm 5.01$ & $25.20 \pm 4.39$ & $\begin{aligned} \mathrm{t}(9) & =-4.478 \\
\mathrm{p} & =0.002\end{aligned}$ \\
\hline \multicolumn{2}{|l|}{ Self-Regulation (MAIA) } & $9.60 \pm 3.80$ & $14.80 \pm 2.04$ & $\begin{aligned} t(9) & =-5.600 \\
p & =0.000\end{aligned}$ \\
\hline \multicolumn{2}{|l|}{ Trusting (MAIA) } & $9.20 \pm 3.36$ & $11.80 \pm 2.86$ & $\begin{aligned} t(9) & =-4.628 \\
p & =0.001\end{aligned}$ \\
\hline \multirow[t]{3}{*}{$\begin{array}{l}\text { Burnout Self-Test and } \\
\text { the Maslach Burnout } \\
\text { Inventory (BST/MBI) }\end{array}$} & Burnout & $9.60 \pm 6.753$ & $13.20 \pm 10.94$ & $\begin{array}{l}\mathrm{t}=-2.16 \\
\mathrm{p}=0.058\end{array}$ \\
\hline & Depersonalisation & $9.50 \pm 7.76$ & $6.40 \pm 5.50$ & $\begin{aligned} \mathrm{z}=- & 1.72, \mathrm{p}= \\
& 0.085\end{aligned}$ \\
\hline & $\begin{array}{l}\text { Personal } \\
\text { Achievement }\end{array}$ & $34.90 \pm 11.05$ & $39.20 \pm 8.60$ & $\begin{array}{c}\mathrm{z}=-2.30, \mathrm{p}= \\
0.021\end{array}$ \\
\hline \multicolumn{2}{|c|}{$\begin{array}{l}\text { Five Faced Mindfulness questionnaire: short } \\
\text { form (FFMQ-SF) }\end{array}$} & $65.8 \pm 5.73$ & $68.10 \pm 6.08$ & $\begin{array}{c}\mathrm{z}=-1.17, \mathrm{p}= \\
0.241\end{array}$ \\
\hline
\end{tabular}




\begin{tabular}{|l|c|c|c|}
\cline { 2 - 4 } Acting with Awareness (FFMQ-SF) & $8.30 \pm 2.49$ & $6.60 \pm 1.95$ & $\begin{array}{c}\mathrm{t}(9)=3.431, \mathrm{p} \\
=0.008\end{array}$ \\
\hline $\begin{array}{l}\text { Santa Clara Brief Compassion Scale } \\
\text { (SCBC) }\end{array}$ & $23.5 \pm 5.359$ & $27.6 \pm 4.03$ & $\begin{array}{c}\mathrm{t}(9)=-2.527, \mathrm{p} \\
=0.032\end{array}$ \\
\hline $\begin{array}{l}\text { The Depression, Anxiety and Stress Scale } \\
\text { (DASS 21) }\end{array}$ & $30.00 \pm 14.36$ & $21.00 \pm 13.67$ & $\mathrm{t}(9)=1.85, \mathrm{p}=$ \\
& & & 0.097 \\
\hline $\begin{array}{l}\text { The Positive and Negative Affect Schedule } \\
\text { (PANAS) }\end{array}$ & $31.30 \pm 8.06$ & $39.70 \pm 2.83$ & $\begin{array}{c}\mathrm{z}=-2.80, \mathrm{p}= \\
0.005\end{array}$ \\
\hline Positive Affect of (PANAS) & $31.30 \pm 8.05$ & $39.70 \pm 2.83$ & $\begin{array}{c}\mathrm{t}(9)=-3.763, \\
\mathrm{p}=0.004 .\end{array}$ \\
\hline Perceived Stress Scale & & & $\mathrm{z}=-1.899, \mathrm{p}=$ \\
& $17.70 \pm 7.67$ & $13.30 \pm 3.91$ & 0.058 \\
\hline
\end{tabular}

Table 5: Analysis comparing change score (pre - post meditation) for the two groups face to face and self-directed

\begin{tabular}{|c|c|c|c|c|}
\hline \multicolumn{2}{|c|}{ Outcome Variable } & $\begin{array}{c}\text { Post } \\
\text { Meditation } \\
\text { (FFG) }\end{array}$ & $\begin{array}{c}\text { Post Meditation } \\
\text { (SDG) }\end{array}$ & $\begin{array}{c}\text { Statistical } \\
\text { analyses values } \\
(\mathbf{t} / \mathbf{u}, \mathbf{p}) \\
\text { P Value }\end{array}$ \\
\hline \multicolumn{2}{|c|}{$\begin{array}{l}\text { Multidimensional Assessment of } \\
\text { Interceptive Awareness (MAIA). }\end{array}$} & $28 \pm 14$ & $-6.66 \pm 22.12$ & $\begin{array}{c}\mathrm{p}= \\
\mathrm{e} \\
2.034, \mathrm{u}= \\
2.500\end{array}$ \\
\hline \multicolumn{2}{|c|}{ Attention Regulation (MAIA) } & $7.70 \pm 5.43$ & $-5.33 \pm 5.50$ & $\begin{array}{c}\mathrm{p}=0.004, \mathrm{t}(11)=- \\
3.663\end{array}$ \\
\hline \multicolumn{2}{|c|}{ Self-Regulation (MAIA) } & $5.20 \pm 2.93$ & $-1.66 \pm 5.50$ & $\begin{array}{c}\mathrm{p}=0.013, \mathrm{t}(11)=- \\
2.942\end{array}$ \\
\hline \multicolumn{2}{|c|}{ Trusting (MAIA) } & $2.60 \pm 1.77$ & $-1.00 \pm 5.56$ & $\begin{array}{c}\mathrm{p}=0.083, \mathrm{t}(11)=- \\
1.908\end{array}$ \\
\hline \multirow{2}{*}{$\begin{array}{l}\text { Burnout Self- } \\
\text { Test and the } \\
\text { Maslach } \\
\text { Burnout }\end{array}$} & Burnout & $3.6 \pm 5.25$ & $1.33 \pm 6.42$ & $\begin{array}{c}\mathrm{p}=0.619, \mathrm{t}(11)= \\
0.628\end{array}$ \\
\hline & Depersonalisation & $3.1 \pm 6.15$ & $1 \pm 4.58$ & $\mathrm{p}=0.733, \mathrm{u}=13$ \\
\hline
\end{tabular}




\begin{tabular}{|l|c|c|c|}
\hline $\begin{array}{l}\text { Inventory } \\
\text { (BST/MBI) }\end{array}$ & $\begin{array}{l}\text { Personal } \\
\text { Achievement }\end{array}$ & $4.30 \pm 4.83$ & $\mathrm{p}=0.73 \pm 9.29, \mathrm{u}=13$, \\
\hline $\begin{array}{l}\text { Five Faced Mindfulness } \\
\text { Questionnaire: short form (FFMQ- } \\
\text { SF) }\end{array}$ & $2.3 \pm 5.45$ & $3.66 \pm 6.02$ & $\mathrm{p}=0.692, \mathrm{u}=12$ \\
\hline Acting with Awareness (FFMQ-SF) & $-1.70 \pm 1.56$ & $0.66 \pm 2.08$ & $\mathrm{p}=0.055, \mathrm{t}(11)=$ \\
& & $-1 \pm 5.29$ & $\mathrm{p}=0.025, \mathrm{t}(11)=-$ \\
\hline $\begin{array}{l}\text { Santa Clara Brief Compassion Scale } \\
\text { Scale (DASS 21) }\end{array}$ & $4.1 \pm 5.13$ & & 1.835 \\
\hline $\begin{array}{l}\text { The Positive and Negative Affect } \\
\text { Schedule (PANAS) }\end{array}$ & $8.40 \pm 7.06$ & $-1 \pm 5$ & $\mathrm{p}=0.049, \mathrm{u}=3.00$ \\
\hline $\begin{array}{l}\text { Positive Affect of (PANAS) } \\
\text { Perceived Stress Scale (PSS) }\end{array}$ & $-4.4 \pm 6.76$ & $-6 \pm 4.35$ & $\mathrm{p}=0.619, \mathrm{t}(11)=$ \\
& & & 0.554 \\
\hline
\end{tabular}

Data are presented as mean $\pm S D$, and statistical analysis. A Mann-Whitney U Test (T test) was used to compare the mean difference scores between the face to face groups (FFGs), and self-directed group $(S D G)$. 


\section{Discussion}

The first aim of this study was to investigate whether mindfulness has an ability to increase therapists' body-awareness and reduce their burnout at their workplace, besides looking at the positive effects of $\mathrm{MM}$ on their personal experiences after four weeks of formal and informal practise. The second aim was to understand the efficacy of each method in terms of an applied MMP and whether it was effective in a group of therapists. The novel findings in this study were that, MM has positively affected therapists, in particular in the FFGs. More specifically, variables which positively changed in the FFGs were attention-regulation, selfregulation, trusting, acting with awareness, positive affect, compassion and personalachievement. In other words, therapists obtained beneficial results from mindfulness as a result of their regular practise in both formal and informal practise. In general, therapists' body-awareness increased after they received a brief form of MMP. Body-awareness was assessed through MAIA and FFMQ scales. Notably, in the FFGs "almost significant" changes were found in other variables (depersonalisation, burnout); however, there were no statistical changes in some of the remaining scales that had been included (depression, anxiety, stress, non-judging, non-reactivity, describing and observing).

However, no significant differences were found in the SDGs in all variables that are mentioned above. An explanation that emerges from statistical results can be estimated via two main reasons. The first, is that mindfulness meditation practice mainly involves changes in attitude and attention, whereas physiotherapy depends on physical movements. The second, posits that therapists in the SDG applied mindfulness by themselves and they obtained guidance only through a CD. In addition to that, regular MM might have also affected therapists. Nevertheless, there was no potential expectation that might have affected therapists parallel to the MM during the period of the program. To further illuminate the 
effects of MMP, each measurement that is used with therapists individually will be explained in the sections that follow.

\section{Body-Awareness}

The results observed that there were significant changes in mean difference scores between groups and for the FFDs. Our perspective behind these results was that therapists cultivated greater attention-regulation, self-regulation and trusting after MP. The advantage might have occurred because the therapists received further guidelines regarding mindfulness training. This was specifically, during the formal session of the MMP that they practised with the primary researcher. Consistent with Kabat-Zinn [42] it was stated that the word "practise" did not explain the competition level or performance, it simply demonstrated a cultivation of mindfulness. In other words, the core of mindfulness is being present in the moment and not achieving better performance. Along with other researchers, Maloney et al. [43] emphasised that through mindfulness practise moment-to-moment, it is possible to cultivate a greater awareness of emotions and body sensations, by accepting them as they occur without changing or judging the experiences. Other findings by Tsur et al. [44] indicated that mindfulness can lead to a greater body awareness. Additionally, a study by Jain et al. [45] stated that through a brief form of MM practise and a somatic relaxation training, there was an improvement in positive mood and less distress compared to the control group.

\section{Mindfulness}

The finding indicated that there were significant changes in the mean differences scores between groups for the FFGs. The most important finding was that there was an improvement in acting with awareness, in the FFGs compared to the SDG. To illustrate that, therapists in the FFGs practised ninety minutes of the MM per week and in addition they were supposed to practise twenty minutes per day. According to Kabat-Zinn [42] practising 
mindfulness every day is the most important point to remember. Nevertheless, the findings showed no significant differences observed in pre and post mindfulness for both groups. It can be appraised that the reason for that is FFMQ is a trait scale not a state scale that might influence therapists' scores.

Burnout (Depersonalisation, personal achievement, Burnout)

Expectedly, results showed that there were significant differences in the mean scores between pre and post mindfulness for the FFGs. Therapists in this group gained a reduction in their burnout level. In turn, this explained the effectiveness of MMP on therapists. These findings also coincided with other research that mentioned the effects of MBSR in reducing burnout and improving well-being in a healthy population [46, 47 and 48]. On the other hand, no significant changes were found in the SDG in the pre and post MMP. Similarly, there were no significant changes between the groups in their means scores. It is noteworthy that, the burnout level reduced in the FFGs compared to the SDG. The potential reason might emerge from the fact that the FFGs attended one 60-90 minute formal session with a primary investigator. Moreover, there was an opportunity to share an idea prior and post all sessions.

The second subscale regarding burnout of the self-test is depersonalisation. Findings revealed that there were significant differences in the FFGs in the pre and post MMP. As noted above, and in addition to the informal MP, therapists attended a formal session each week. Therefore, it can be realised that there were reductions in the depersonalisation level with therapists in the FFGs. The outcomes were consistent with a study by Cohen-Katz et al. [46] that found depersonalisation and emotional exhaustion had significantly changed in nurses after 8 weeks of the MBSR program. On the contrary, no significant differences in 
the SDG were observed. As well, no significant differences were found between groups in their means scores.

Therapists who took part in the SDG were from other countries with different time schedules that might have affected their level of depersonalisation. In addition, therapists in the SDG practised meditation by themselves. Therefore, they carried on the MMP by themselves without additional guides or sharing an idea with the primary researcher before and after sessions as therapists did in FFGs. Another possibility is that therapists may experience memories of past unpleasant events during the MP. These thoughts often subside as a result of doing the exercises repeatedly and with practice, allowing thoughts to become less intrusive over time. Furthermore, the therapists might have felt that MMP interfered with their belief systems, which affected their depersonalisation state.

The final subscale to assess the BST scale is personal-achievement. Maslach et al. [21] revealed that in order to determine personal-achievement as a component of burnout, it can be noticed that there was a negative judging and having feelings of not being capable of changing the situation. This can lead to distressing feelings despite spending effort. As a result, individuals will be in doubt as to whether they have an ability to achieve their objectives.

Our findings indicated that personal-achievement increased in the FFGs. As data showed, there were significant changes in pre and post MMP. The possible explanation was that therapists had less negative self-efficacy toward themselves and they believed in their abilities after they had received four weeks of MMP. The scores in the SDGs showed that personal-achievement had no significant differences in pre and post MP. As such, there were significant differences found between groups in their means differences scores. 


\section{Positive and Negative Affect of MMP}

The results observed that there were significant changes in the pre and post mindfulness programs in the FFGs. More specifically, the evidence in this study regarding PANAS, showed that there was a clear positive change in the FFGs regarding to "positive subscale" after they practised MMP. The expectation was that because of the daily practice of mindfulness, the FFGs would have clear changes in positive affect. This assumption was based on therapists in the particular period of MMP not practising any other program aligned with MMP.

Likewise, data has also discovered that there were significant differences in the means differences scores between groups for the FFGs. Constant with what was stated above, Brockman et al. [49] indicated that daily mindfulness practise is related to greater positive effects and less negative effects in supporting the value of MP. Another finding by Chambers et al. [50] supports the effectiveness of a daily training of mindfulness in reducing depressive symptoms and also an enhancement of cognitive function.

On the other side, the findings in this study have shown no significant differences in the pre and post MMP for the SDG. Our interpretation is that, the rate of informal MP that therapists in the SDG trained in was not enough to improve their positive affect scores.

\section{Compassion}

Data showed that the compassion for the FFGs had significantly changed after they had participated in the MMP. This is explained by the fact that therapists followed and practiced mindfulness at a regular time during their participation. In addition, mindfulness helped therapists to increase their compassion, after gaining daily benefits from mindfulness. The reason for that is that compassion and loving-kindness are a part of the program. In other 
words, the CD of MBSR has a guide to improve and educate those skills, and also the possibility of integrating compassion in their daily tasks during their work as therapists. Thus, there were advantages in the level of compassion between the pre and post MMP. Strikingly, this supports other evidence regarding the effects of MMP in increasing compassion, [51-53].

In contrast, there were no significant differences in the SDG, although changes have been calculated between pre and post MMP. Our explanation is that therapists in the SDG might have not had a daily basis for practicing MM like their peers in the FFGs. This in turn, might have had an effect on their level of compassion.

\section{Perceived Stress}

Despite of the huge amount of research that has been done on MBSR, there is numerous evidence that reports the effectiveness of MBSR in reducing stress with a healthy population [54-57]. In addition, with the positive effect of MBSR, a lot of research has been done with the clinical population in reducing stress symptoms [58-60]. However, our findings displayed that there were no significant differences found in the pre and post MMP for both groups. At the same time, no significant changes were found in the means differences between the groups. This might be because of the level of stress in each group at the beginning of the program. Besides, mindfulness is a new skill with no prior experience and the nature of the practice is a very calm technique that might have affected their stress levels. Another prediction is that, therapists' applied mindfulness through the CD guides, particularly in the SDG. Therefore, the CD might have oriented them to pay more attention to focusing on reducing stress levels through a technological tool. 


\section{Depression, Anxiety and Stress}

Our findings showed that there were no significant differences found in both FFGs as well as the SDG in the pre and post mindfulness practise. Further, there were no significant changes between groups in the means differences scores. Even though a sizable body of literature has shown that MM practise has a positive influence on therapists in decreasing their level of depression such those of Serpa et al. [61] and Greeson et al. [62] whose findings showed that depressive symptoms had significantly reduced in 79 veterans and 322 adults respectively. Moreover, Allexandre et al. [63] and Ivtzan et al. [64] found through an online intervention that mindfulness had positive effects in improving wellbeing and also workplace stress. Moreover, a study by Goldin and Gross [65] found that the MBSR program had had positive effects in reducing anxiety, depression and improved self-esteem in people with a social anxiety disorder. Originally MBSR was a clinical approach that included regular $\mathrm{MM}$ practise. Emotion management and stress reduction are the core objectives in MBSR [66]. Related to the findings in this study, it can be predicated that therapists might have had the same mind state once they had been asked to fill up the DASS scale in both terms of the programme.

In view of these findings and perceptions, therapists in the FFGs gained benefits from MP to improve their body-awareness and also higher scores in the personal achievement, as a subscale of the BST. Importantly, the results of this study have also unveiled that, the FFGs was better than the SDG as a method of delivery of the mindfulness program.

Overall, the present study focused on the potential role of mindfulness training and body awareness in therapist self-care and burnout prevention. Another noteworthy, further lines of inquiry could focus on whether mindfulness training could provide skills that might also help therapists better meet the needs of their clients. Indeed, Arvinen-Barrow et al. [67] 
stated that 'increasing physiotherapist's awareness of the different techniques available and the ways in which psychological interventions can be successfully integrated into physiotherapy process would be beneficial' [67, p.65]. Along the same line, Hemmings and Povey [68] indicated that future direction of physiotherapy rehabilitation needs more emphasis on increasing the level of knowledge about using psychological interventions in physiotherapy rehabilitation.

This was echoed by Shapiro and Carlson [69] who have suggested that therapists through mindfulness training could improve the therapeutic outcomes by cultivating selfcompassion, accepting attention, self-attunement, empathy and the ability of emotion regulation. Hopefully the results of our study will inspire the above mentioned lines of inquire that could more insight on how mindfulness can be of the benefit for both the caregivers and care receivers.

\section{Strengths and limitations of this study}

- To the best of our knowledge, this is the first study that has used internet-based technology (websites, skype calls and online surveys) as a part of its methodology to assess MMP with therapists.

- Therapists were able to be involved in this study from anywhere in the world thanks to the website that was created especially for the purposes of this study.

- In this study different psychological variables have been assessed with therapists such as body-awareness, mindfulness, positive and negative affect of MMP, compassion, burnout, and stress. This allowed obtaining a more holistic approach to understand various aspects regarding mindfulness and therapists' experiences.

- Each therapist who wanted to form part of the study had to engage with the research for a period of nearly two months. Therefore, the researchers encountered some issues with 
recruitment and commitment of the participants as it was difficult for many therapists to commit for that length of time.

- Another potential limitation of the current study was that mindfulness meditation sessions were carried out individually with therapists in the FFGs. There are two reasons for that. The first, is that it was not possible for therapists in the FFGs to attend at the same time because of their busy work and complications in terms of coordination of their diary. Secondly, there was the issue of the time zone difference between therapists who practised through the skype method located in countries with different time zones. This made a group skype call not being a feasible option.

- There was not any control mechanism in place to verify the engagement of therapists in the self-directed group to the tasks of listening to the $\mathrm{CD}$ or to confirm objectively their active commitment in the mindfulness meditation.

\section{Recommendations}

- Our results indicated that a mindfulness programme is more effective when practising with a mindfulness instructor rather than alone, especially when the participant has with no prior experience in participating in mindfulness programme.

- Further research will have to be conducted in order to determine the effect of practicing for a short duration of time, in particular 5 to 10 minutes pre and post treatment process. This is in addition to the formal and self-directed practice.

- More research in this field could include into the mindfulness programme sessions of stretching exercises or yoga movements and explore if this adds into gaining more bodyawareness and less feeling of burnout. 


\section{Words count: 7227}

\section{References}

1. Stahl, Bob and Elisha Goldstein. A Mindfulness-Based Stress Reduction Workbook New Harbinger Publications, 2010.

2. Chiesa, Alberto and Alessandro Serretti. "Mindfulness-Based Interventions for Chronic Pain: A Systematic Review of the Evidence." The Journal of Alternative and Complementary Medicine 17, no. 1 (2011): 83-93.

3. La Forge, Ralph. "Aligning Mind and Body: Exploring the Disciplines of Mindful Exercise." ACSM's Health \& Fitness Journal 9, no. 5 (2005): 7-14.

4. Silverton, Sarah. The Mindfulness Breakthrough: The Revolutionary Approach to Dealing with Stress, Anxiety and Depression Watkins Media Limited, 2012.

5. Mills, Nigel and Janet Allen. "Mindfulness of Movement as a Coping Strategy in Multiple Sclerosis: A Pilot Study." General Hospital Psychiatry 22, no. 6 (2000): 425431.

6. Baer, Ruth A., Gregory T. Smith, and Kristin B. Allen. "Assessment of Mindfulness by Self-Report: The Kentucky Inventory of Mindfulness Skills." Assessment 11, no. 3 (2004): 191-206.

7. Marlatt, G. Alan and Dennis M. Donovan. Relapse Prevention: Maintenance Strategies in the Treatment of Addictive Behaviors Guilford Press, 2005.

8. Hayes, Steven C., Kirk D. Strosahl, and Kelly G. Wilson. Acceptance and Commitment Therapy Guilford Press New York, 1999. 
9. Segal, Zindel V., John D. Teasdale, J. Mark Williams, and Michael C. Gemar. "The mindfulness-based Cognitive Therapy Adherence Scale: Inter-rater Reliability, Adherence to Protocol and Treatment Distinctiveness." Clinical Psychology \& Psychotherapy 9, no. 2 (2002): 131-138.

10. Kabat-Zinn, Jon. "An Outpatient Program in Behavioral Medicine for Chronic Pain Patients Based on the Practice of Mindfulness Meditation: Theoretical Considerations and Preliminary Results." General Hospital Psychiatry 4, no. 1 (1982): 33-47.

11. Kabat-Zinn, Jon. "Full Catastrophe Living: The Program of the Stress Reduction Clinic at the University of Massachusetts Medical Center." (1990).

12. Klappa, Susan G., Lois E. Fulton, Lauren Cerier, Alexa Peña, Andrew Sibenaller, and Scott P. Klappa. "Compassion Fatigue among Physiotherapist and Physical Therapists Around the World." Health Education3, no. 5 (2015): 124-137.

13. Gh, Maghsoud Eivazi, Amin Alilou, Sara Fereydounnia, and Zohre Zaki. "Factors Associated with Burnout Syndrome in Physiotherapy Staff: A Questionnaire Study.

14. http://www.csp.org.uk/professional-union/union-support/health-safety/occupationalstress.

15. Stamm, Beth Hudnall. "The Concise ProQOL Manual." (2010).

16. Pavlakis, Andreas, Vasilios Raftopoulos, and Mamas Theodorou. "Burnout Syndrome in Cypriot Physiotherapists: A National Survey." BMC Health Services Research 10, no. 1 (2010): 63 .

17. Ogiwara, Shimpachiro and Hisano Hayashi. "Burnout Amongst Physiotherapists in Ishikawa Prefecture." Journal of Physical Therapy Science 14, no. 1 (2002): 7-13. 
18. Painter, Jane, Duane Akroyd, Sharon Elliot, and Robert D. Adams. "Burnout among Occupational Therapists." Occupational Therapy in Health Care 17, no. 1 (2003): 6378.

19. Tragea, P., D. Damigos, V. Mavreas, and M. Gouva. "Burn Out among Greek Physical Therapists." (2012).

20. Pustułka-Piwnik, Urszula, Zdzisław Jan Ryn, Łukasz Krzywoszański, and Joanna Stożek. "Burnout Syndrome in Physical Therapists-Demographic and Organizational Factors." Medycyna Pracy 65, no. 4 (2014): 453-462.

21. Maslach, C. and SE Jackson. "Maslach Burnout Inventory-Human Services Survey (MBBHSS)." C.Maslach, SE Jackson \& MP Leiter, MBI Manual (3rd Ed.).Mountain View, CA: CPP (1996).

22. Landsman-Dijkstra, J. J., R. van Wijck, and J. W. Groothoff. "The Long-Term Lasting Effectiveness on Self-Efficacy, Attribution Style, Expression of Emotions and Quality of Life of a Body Awareness Program for Chronic a-Specific Psychosomatic Symptoms." Patient Education and Counseling 60, no. 1 (Jan, 2006): 66-79. doi:S0738-3991(04)00407-0 [pii].

23. Shapiro, Shauna L., John A. Astin, Scott R. Bishop, and Matthew Cordova. "Mindfulness-Based Stress Reduction for Health Care Professionals: Results from a Randomized Trial." International Journal of Stress Management 12, no. 2 (2005): 164.

24. Schenström, Anna, Sten Rönnberg, and Owe Bodlund. "Mindfulness-Based Cognitive Attitude Training for Primary Care Staff: A Pilot Study." Complementary Health Practice Review 11, no. 3 (2006): 144-152. 
25. Loera, Barbara, Daniela Converso, and Sara Viotti. "Evaluating the Psychometric Properties of the Maslach Burnout Inventory-Human Services Survey (MBI-HSS) among Italian Nurses: How Many Factors must a Researcher Consider?" PLoS One 9, no. 12 (2014): e114987.

26. Mehling, Wolf E., Cynthia Price, Jennifer J. Daubenmier, Mike Acree, Elizabeth Bartmess, and Anita Stewart. "The Multidimensional Assessment of Interoceptive Awareness (MAIA)." PloS One 7, no. 11 (2012): e48230.

27. Baer, Ruth A., Gregory T. Smith, Jaclyn Hopkins, Jennifer Krietemeyer, and Leslie Toney. "Using Self-Report Assessment Methods to Explore Facets of Mindfulness." Assessment 13, no. 1 (2006): 27-45.

28. Bohlmeijer, Ernst, Peter M. ten Klooster, Martine Fledderus, Martine Veehof, and Ruth Baer. "Psychometric Properties of the Five Facet Mindfulness Questionnaire in Depressed Adults and Development of a Short Form." Assessment 18, no. 3 (2011): 308-320.

29. Hwang, Jeong Yeon, Thomas Plante, and Katy Lackey. "The Development of the Santa Clara Brief Compassion Scale: An Abbreviation of Sprecher and Fehr's Compassionate Love Scale." Pastoral Psychology56, no. 4 (2008): 421-428.

30. Sprecher, Susan and Beverley Fehr. "Compassionate Love for Close Others and Humanity." Journal of Social and Personal Relationships 22, no. 5 (2005): 629-651.

31. Plante, Thomas G. and Jesus Mejia. "Psychometric Properties of the Santa Clara Brief Compassion Scale." Pastoral Psychology 65, no. 4 (2016): 509-515. 
32. Watson, David, Lee A. Clark, and Auke Tellegen. "Development and Validation of Brief Measures of Positive and Negative Affect: The PANAS Scales." Journal of Personality and Social Psychology 54, no. 6 (1988): 1063.

33. Schmukle, Stefan C., Boris Egloff, and Lawrence R. Burns. "The Relationship between Positive and Negative Affect in the Positive and Negative Affect Schedule." Journal of Research in Personality 36, no. 5 (2002): 463-475.

34. Watson, David and James W. Pennebaker. "Health Complaints, Stress, and Distress: Exploring the Central Role of Negative Affectivity." Psychological Review 96, no. 2 (1989): 234.

35. Watson, David, Lee A. Clark, Curtis W. McIntyre, and Stacy Hamaker. "Affect, Personality, and Social Activity." Journal of Personality and Social Psychology 63, no. 6 (1992): 1011.

36. Burger, Jerry M. and David F. Caldwell. "Personality, Social Activities, Job-Search Behavior and Interview Success: Distinguishing between PANAS Trait Positive Affect and NEO Extraversion." Motivation and Emotion 24, no. 1 (2000): 51-62.

37. Becoña, Elisardo, Fernando L. Vázquez, María José Fuentes, and María del Carmen Lorenzo. "Anxiety, Affect, Depression and Cigarette Consumption." Personality and Individual Differences 26, no. 1 (1998): 113-119.

38. Cohen, S. and G. Williamson. "Perceived Stress in a Probability Sample of the United States. the Social Psychology of Health: Claremont Symposium on Applied Social Psychology. Edited by: Spacapan S, Oskamp S. 1988." (1988).

39. Andreou, Eleni, Evangelos C. Alexopoulos, Christos Lionis, Liza Varvogli, Charalambos Gnardellis, George P. Chrousos, and Christina Darviri. "Perceived Stress 
Scale: Reliability and Validity Study in Greece." International Journal of Environmental Research and Public Health 8, no. 8 (2011): 3287-3298.

40. Lovibond, Peter F. and Sydney H. Lovibond. "The Structure of Negative Emotional States: Comparison of the Depression Anxiety Stress Scales (DASS) with the Beck Depression and Anxiety Inventories." Behaviour Research and Therapy 33, no. 3 (1995): 335-343.

41. Crawford, John R., Paul H. Garthwaite, Caroline J. Lawrie, Julie D. Henry, Marie A. MacDonald, Jane Sutherland, and Priyanka Sinha. "A Convenient Method of Obtaining Percentile Norms and Accompanying Interval Estimates for self-report Mood Scales (DASS, DASS-21, HADS, PANAS, and sAD)." British Journal of Clinical Psychology 48, no. 2 (2009): 163-180.

42. Kabat-Zinn, Jon. Wherever You Go, there You are: Mindfulness Meditation in Everyday Life Hachette UK, 2009.

43. Maloney, Jacqueline E., Molly Stewart Lawlor, Kimberly A. Schonert-Reichl, and Jenna Whitehead. "A Mindfulness-Based Social and Emotional Learning Curriculum for School-Aged Children: The MindUP Program." In Handbook of Mindfulness in Education, 313-334: Springer, 2016.

44. Tsur, Noga, Nirit Berkovitz, and Karni Ginzburg. "Body Awareness, Emotional Clarity, and Authentic Behavior: The Moderating Role of Mindfulness." Journal of Happiness Studies 17, no. 4 (2016): 1451-1472.

45. Jain, Shamini, Shauna L. Shapiro, Summer Swanick, Scott C. Roesch, Paul J. Mills, Iris Bell, and Gary ER Schwartz. "A Randomized Controlled Trial of Mindfulness 
Meditation Versus Relaxation Training: Effects on Distress, Positive States of Mind, Rumination, and Distraction." Annals of Behavioral Medicine 33, no. 1 (2007): 11-21.

46. Cohen-Katz, J., S. D. Wiley, T. Capuano, D. M. Baker, S. Kimmel, and S. Shapiro. "The Effects of Mindfulness-Based Stress Reduction on Nurse Stress and Burnout, Part II: A Quantitative and Qualitative Study." Holistic Nursing Practice 19, no. 1 (Jan-Feb, 2005): 26-35.

47. Gold, Eluned, Alistair Smith, Ieuan Hopper, David Herne, Glenis Tansey, and Christine Hulland. "Mindfulness-Based Stress Reduction (MBSR) for Primary School Teachers." Journal of Child and Family Studies 19, no. 2 (2010): 184-189.

48. Goodman, Matthew J. and John B. Schorling. "A Mindfulness Course Decreases Burnout and Improves Well-being among Healthcare Providers." The International Journal of Psychiatry in Medicine 43, no. 2 (2012): 119-128.

49. Brockman, Robert, Joseph Ciarrochi, Philip Parker, and Todd Kashdan. "Emotion Regulation Strategies in Daily Life: Mindfulness, Cognitive Reappraisal and Emotion Suppression." Cognitive Behaviour Therapy46, no. 2 (2017): 91-113.

50. Chambers, Richard, Barbara Chuen Yee Lo, and Nicholas B. Allen. "The Impact of Intensive Mindfulness Training on Attentional Control, Cognitive Style, and Affect." Cognitive Therapy and Research 32, no. 3 (2008): 303-322.

51. Kuyken, Willem, Ed Watkins, Emily Holden, Kat White, Rod S. Taylor, Sarah Byford, Alison Evans, Sholto Radford, John D. Teasdale, and Tim Dalgleish. "How does Mindfulness-Based Cognitive Therapy Work?" Behaviour Research and Therapy 48, no. 11 (2010): 1105-1112. 
52. Neff, Kristin D. and Christopher K. Germer. "A Pilot Study and Randomized Controlled Trial of the Mindful self-compassion Program." Journal of Clinical Psychology 69, no. 1 (2013): 28-44.

53. Condon, Paul, Gaëlle Desbordes, Willa B. Miller, and David DeSteno. "Meditation Increases Compassionate Responses to Suffering." Psychological Science 24, no. 10 (2013): 2125-2127.

54. Weinstein, Netta, Kirk W. Brown, and Richard M. Ryan. "A Multi-Method Examination of the Effects of Mindfulness on Stress Attribution, Coping, and Emotional Well-being." Journal of Research in Personality43, no. 3 (2009): 374-385.

55. Erogul, Mert, Gary Singer, Thomas McIntyre, and Dimitre G. Stefanov. "Abridged Mindfulness Intervention to Support Wellness in First-Year Medical Students." Teaching and Learning in Medicine 26, no. 4 (2014): 350-356.

56. Sallon, Sarah, Deborah Katz-Eisner, Hila Yaffe, and Tali Bdolah-Abram. "Caring for the Caregivers: Results of an Extended, Five-Component Stress-Reduction Intervention for Hospital Staff." Behavioral Medicine 43, no. 1 (2017): 47-60.

57. McConville, Janet, Rachael McAleer, and Andrew Hahne. "Mindfulness Training for Health Profession Students-The Effect of Mindfulness Training on Psychological Well-being, Learning and Clinical Performance of Health Professional Students: A Systematic Review of Randomized and Non-Randomized Controlled Trials." Explore: The Journal of Science and Healing 13, no. 1 (2017): 26-45.

58. Carlson, Linda E., Zenovia Ursuliak, Eileen Goodey, Maureen Angen, and Michael Speca. "The Effects of a Mindfulness Meditation-Based Stress Reduction Program on 
Mood and Symptoms of Stress in Cancer Outpatients: 6-Month FollowUp." Supportive Care in Cancer 9, no. 2 (2001): 112-123.

59. Minor, Holly G., Linda E. Carlson, Michael J. Mackenzie, Kristin Zernicke, and Lanice Jones. "Evaluation of a Mindfulness-Based Stress Reduction (MBSR) Program for Caregivers of Children with Chronic Conditions." Social Work in Health Care 43, no. 1 (2006): 91-109.

60. Reich, Richard R., Cecile A. Lengacher, Carissa B. Alinat, Kevin E. Kip, Carly Paterson, Sophia Ramesar, Heather S. Han, Roohi Ismail-Khan, Versie JohnsonMallard, and Manolete Moscoso. "Mindfulness-Based Stress Reduction in PostTreatment Breast Cancer Patients: Immediate and Sustained Effects Across Multiple Symptom Clusters." Journal of Pain and Symptom Management 53, no. 1 (2017): 8595.

61. Serpa, J. G., S. L. Taylor, and K. Tillisch. "Mindfulness-Based Stress Reduction (MBSR) Reduces Anxiety, Depression, and Suicidal Ideation in Veterans." Medical Care 52, no. 12 Suppl 5 (Dec, 2014): S19-24. doi:10.1097/MLR.0000000000000202 [doi].

62. Greeson, Jeffrey M., Moria J. Smoski, Edward C. Suarez, Jeffrey G. Brantley, Andrew G. Ekblad, Thomas R. Lynch, and Ruth Quillian Wolever. "Decreased Symptoms of Depression After Mindfulness-Based Stress Reduction: Potential Moderating Effects of Religiosity, Spirituality, Trait Mindfulness, Sex, and Age." The Journal of Alternative and Complementary Medicine 21, no. 3 (2015): 166-174.

63. Allexandre, D., A. M. Bernstein, E. Walker, J. Hunter, M. F. Roizen, and T. J. Morledge. "A Web-Based Mindfulness Stress Management Program in a Corporate 
Call Center: A Randomized Clinical Trial to Evaluate the Added Benefit of Onsite Group Support." Journal of Occupational and Environmental Medicine 58, no. 3 (Mar, 2016): 254-264. doi:10.1097/JOM.0000000000000680 [doi].

64. Ivtzan, Itai, Tarli Young, Janis Martman, Allison Jeffrey, Tim Lomas, Rona Hart, and Francisco Jose Eiroa-Orosa. "Integrating Mindfulness into Positive Psychology: A Randomised Controlled Trial of an Online Positive Mindfulness Program." Mindfulness 7, no. 6 (2016): 1396-1407.

65. Goldin, Philippe R. and James J. Gross. "Effects of Mindfulness-Based Stress Reduction (MBSR) on Emotion Regulation in Social Anxiety Disorder." Emotion 10, no. 1 (2010): 83.

66. Bishop, Scott R. "What do we really Know about Mindfulness-Based Stress Reduction?" Psychosomatic Medicine 64, no. 1 (2002): 71-83.

67. Arvinen-Barrow, Monna, Gillian Penny, Brian Hemmings, and Susan Corr. "UK Chartered Physiotherapists' Personal Experiences in using Psychological Interventions with Injured Athletes: An Interpretative Phenomenological Analysis." Psychology of Sport and Exercise 11, no. 1 (2010): 58-66.

68. Hemmings, B. and L. Povey. "Views of Chartered Physiotherapists on the Psychological Content of their Practice: A Preliminary Study in the United Kingdom." British Journal of Sports Medicine 36, no. 1 (Feb, 2002): 61-64.

69. Shapiro, Shauna L., Gary E. Schwartz, and Ginny Bonner. "Effects of MindfulnessBased Stress Reduction on Medical and Premedical Students." Journal of Behavioral Medicine 21, no. 6 (1998): 581-599. 